\title{
OPERAÇÕES SOCIAIS DA MENTE
}

\section{SOCIAL OPERATIONS OF MIND}

André Leclerc*

RESUMO - Thomas Reid introduziu a noção de operação social da mente na teoria da mente e da linguagem. Seu amigo James Gregory desenvolveu essa noção no contexto da Gramática Universal clássica, particularmente na teoria geral dos modos verbais. A gramática filosófica clássica, antes de Reid e Gregory, pressupõe inter alia que a mente é "autocontida" (self-contained); em outras palavras, que os conteúdos e as operações mentais independem do ambiente natural e social. Algumas dessas operações têm uma estrutura em modus/ dictum que corresponde, grosso modo, à distinção atual entre modo psicológico e conteúdo mental conceitual, análoga à distinção entre força ilocucionária e conteúdo proposicional e que se reflete parcialmente no sistema de modos verbais nas línguas naturais. A famosa Gramática de Port-Royal já indicava uma limitação importante desse modelo de mente autocontida: "On ne se commande pas proprement à soimême", escrevem Arnauld \& Lancelot ("Não se ordena propriamente a si mesmo"). Defenderei que Reid percebeu que o individualismo não permite capturar os aspectos sociais da linguagem e, por isso, viu a necessidade de apresentar uma concepção de mente diferente, antiindividualista. A noção de operação social da mente é a peça fundamental da reforma empreendida por Reid em filosofia da mente. Ademais, ele e Gregory defenderam que as linguagens se formaram particularmente para expressar esses aspectos sociais da linguagem e da mente. PALAVRAS-CHAVE - Thomas Reid. Externismo. Operação social da mente. Teoria da linguagem.

ABSTRACT - Thomas Reid introduced the notion of social operation of mind in the theory of mind and language. His friend James Gregory developed this notion and gave it a meaningful role in classical Universal Grammar, especially in the General Theory of the Moods of Verbs. Before Reid and Gregory, the classical Philosophical Grammar presupposes, inter alia, that the mind is self-contained; in other words, that mental contents and operations are all independent from the natural and social environment. Some of these operations have a modus/dictum structure corresponding, grosso modo, to the actual distinction between

* Doutor em Filosofia pela Universidade do Quebec. Professor de Filosofia no PPG em Filosofia da UFC, Bolsista de Produtividade CNPq Nível 2. < aleclerc@terra.com.br>.

\begin{tabular}{|l|l|l|l|l|l|}
\hline Veritas & Porto Alegre & v. 55 & n. 2 & maio/ago. 2010 & p. 108-125 \\
\hline
\end{tabular}


psychological mode and conceptual mental content, also analogous to the distinction between illocutionary force and propositional content, which is partially reflected in the system of verbal moods of natural languages. The famous Grammaire de Port-Royal already pointed to a serious limitation of this model. Arnauld \& Lancelot wrote: "On ne se commande pas proprement à soi-même" ("One does not command properly to oneself"). I will try to show that Reid realized clearly that what we call today "individualism" does not allow us to characterize adequately the social aspects of language, and consequently headed for a different conception of the mind, an anti-individualist one. The notion of social operation of the mind is the cornerstone of that reform undertaken by Reid in the philosophy of mind. Furthermore, he and Gregory defended that natural languages were created especially to expresses those social aspects of language and mind.

KEYWORDS - Thomas Reid. Externalism. Social operations of mind. Theory of language.

“... on ne se commande pas proprement à soi-même."

(ARNAULD \& LANCELOT, Grammaire générale et raisonnée)

\begin{abstract}
"All languages are equipped to express the social as well as the solitary operations of the mind. Indeed, it may be held that the basic and immediate purpose of language is to express the social operations. A man who had no interactions with other thinking beings would never think of language..."
\end{abstract}

(T. REID, Essays on the Intellectual Powers of Man)

A filosofia da linguagem contemporânea se preocupou muito com os aspectos sociais da linguagem. Parecia uma novidade. Wittgenstein (1953) fez ver a necessidade de critérios públicos que determinam quando uma regra (ou uma palavra) é aplicada corretamente; em última instância, a comunidade "decide", por assim dizer, quais são os jogos de linguagem ou as formas de vida "aceitáveis". Austin (1962), na sua teoria dos atos de fala, mostrou que grande parte dos atos ilocucionários tem como condição de felicidade que pressupõe a existência de uma hierarquia, uma posição de autoridade, ou as regras de um ritual, etc. Quine abre seu opus magnum (Word and Object, 1960) com a famosa frase: "A linguagem é uma arte social". Putnam (1975/1996) e os externistas (ou anti-individualistas) insistem que a linguagem não deve ser comparada a instrumentos que podem ser usados individualmente, como martelos e chaves de fenda, e sim a navios, cujo uso requer uma equipe; a "divisão social do trabalho linguístico" determina até o valor semântico das expressões. O externismo social de Burge (1979/1998), lembrando o "espírito objetivo" de Hegel, mostra como as convenções 
linguísticas de uma comunidade podem determinar o conteúdo mental de um indivíduo. Davidson (1994/2005), outro externista, vai mais longe e faz "o significado" depender de comunicações bem-sucedidas. É a compreensão que dá vida ao significado e permite a sua individuação.

É minha convicção que fenômenos presentes em instituições tão importantes como a linguagem não podem passar totalmente despercebidos por filósofos e cientistas, ao longo de séculos. Afinal, os fenômenos lógico-linguísticos não são fenômenos subatômicos; a princípio, são acessíveis a todos, e séculos de investigações devem inevitavelmente revelar, aqui e ali, o que apressadamente e com orgulho registramos como "novidades" ou "descobertas" de nosso tempo. O ambiente acadêmico, o desenvolvimento das ciências, as técnicas de análise, as abordagens, o ângulo e muitas outras coisas podem mudar, mas, não os fenômenos e os problemas ${ }^{1}$.

Na França e na Inglaterra, no período clássico, a filosofia da linguagem tem um nome: "Gramática Geral ou Universal". A tradição de pesquisa da Gramática Universal iniciou-se na França, em Port-Royal des Champs, e continuou no século seguinte, principalmente na França, na Inglaterra e na Escócia ${ }^{2}$. Os gramáticos filósofos clássicos sempre indicaram a pequena Gramática de Port-Royal (1660) como o início dessa tradição de pesquisa a que dão continuidade. Filósofos do século 18, defensores do racionalismo, do empirismo e do senso comum, aderiram ao projeto de uma Gramática Geral (ou Universal), como Husserl (1901), Chomsky (1966) e Montague (1974) no século 20, independentemente das divergências quanto às teses epistemológicas sobre a origem e a natureza das ideias. Um corpo de princípios relativamente autônomo (em relação às teses epistemológicas e escolas filosóficas) pode ser identificado como o núcleo

1 Se levarmos a sério, simultaneamente, a tese de que os explananda são internos a cada teoria, a tese da incomensurabilidade, a tese da subdeterminação, a tese de que o vocabulário observacional é theory-laden, e negarmos a existência de entidades trans-teóricas, o Paradoxo do Abandono vem logo nos assombrar. Por que abandonar uma teoria para outra supostamente superior, se os explananda nem sequer são os mesmos? Sobre isso, ver Robert Lockie (2003).

2 Os principais autores são: na França, após Arnauld \& Lancelot (1660), Claude Buffier (1709), um filósofo do senso comum que influenciou Reid e os filósofos escoceses no final do século, César Chesneau Du Marsais (1797), um empirista e primeiro grammairien philosophe da grande Encyclopédie de Diderot \& D'Alembert (1751), Nicolas Beauzée (1767), um racionalista e segundo grammairien philosophe da grande Encyclopédie, Condillac (1775), o mais importante filósofo francês da segunda metade do século 18 e principal continuador de Locke, e Destutt de Tracy (1803), empirista, do movimento da "ideologia". Na Inglaterra, James Harris (1751), influenciado por Aristóteles e alguns antigos, influenciou por sua vez James Burnett (1773-1792), conhecido como Lord Monboddo. Os demais gramáticos-filósofos importantes da época clássica são escoceses e filósofos do senso comum: particularmente James Gregory (1790) e James Beattie (1783), que tinha um inimigo famoso na pessoa de David Hume. 
duro de um programa de pesquisa no sentido de Imre Lakatos ${ }^{3}$. A nossa primeira tarefa é identificar esse núcleo duro. A segunda será comparar a concepção de "mente" comum à maioria dos gramáticos-filósofos com a oferecida por Thomas Reid, que consegue superar uma importante limitação da concepção oriunda de Descartes, Port-Royal e dos empiristas, graças à introdução da noção de operação social da mente. A terceira será mostrar como a concepção de mente do Dr. Reid e de seu amigo James Gregory foi usada, particularmente na teoria geral dos modos verbais, onde a intencionalidade do falante na linguagem mais aparece.

\section{0 núcleo duro da Gramática Universal}

A Gramática Universal clássica (GU) tem como objetivo formular as regras constitutivas de qualquer sistema de signos capaz de expressar completamente o pensamento conceitual e de comunicá-lo com eficiência. A GU apóia-se sobre a lógica e a teoria da mente (das ideias). A lógica do período clássico é ainda a lógica aristotélica e a sua concepção do juízo, mas a teoria da mente ou psicologia (racional) filosófica, como veremos mais adiante, é bem diferente daquela de Aristóteles. Ademais, a teoria da mente proposta por Reid é bastante diferente da teoria proposta pelos racionalistas e pelos empiristas.

Um programa de pesquisa é um conjunto de regras metodológicas que prescreve os caminhos a percorrer (heurística positiva) e os caminhos a evitar (heurística negativa). Constitui-se de um núcleo duro, um conjunto de princípios teóricos intocáveis que determina a sua identidade, e de um cinturão de proteção, um conjunto de hipóteses ou teorias auxiliares, que protegem o núcleo duro contra a falsificação, digerem anomalias, respondem a objeções, etc. A aceitação dos princípios do núcleo duro obriga os pesquisadores a rejeitar qualquer hipótese ou teoria que contradiz esses princípios e a promover hipóteses ou teorias auxiliares para facilitar a aplicação dos princípios ou para complementá-los, desenvolvendo-os de modo progressivo em direção a uma maior adequação empírica ${ }^{4}$.

3 Imre Lakatos, The Methodology of Scientific Research Programmes, in: Philosophical Papers, Vol. 1, J. Worrall \& G. Currie (orgs.), p. 8-101.

4 Ver Imre Lakatos, Falsification and the Methodology of Scientific Research Programmes (1970), in: Philosophical Papers, Vol. 1, J. Worrall \& G. P. Currie (orgs.), 1977. Uso aqui nesta seção material já publicado em francês, na revista da Associação Canadense de Filosofia, Dialogue, e num capítulo de livro publicado em 2008, na UFC. Cf. André Leclerc, La Grammaire générale classique en tant que programme de recherche scientifique, in: Dialogue, 77-94; Idem, Linguagem e Natureza na Gramática Universal Clássica, in: Maria Aparecida P. Montenegro; Clara Virginia de Q. Pinheiro; Ivânio Lopes de Azevedo Jr (orgs.), Natureza e Linguagem na Filosofia, p. 13-35. Agradeço aos editores de Dialogue e da coletânea pela permissão de usar material publicado. 
Os princípios do núcleo duro da GU são:

P1: A linguagem é a expressão (ou análise) do pensamento (conceitual), e as palavras significam ideias. GU é, portanto, uma teoria ideacional da linguagem.

P2: A comunicação dos pensamentos é a principal função da linguagem.

P3: O pensamento é o mesmo em toda parte e para todos (postulado da universalidade do pensamento, baseado na tese da uniformidade da natureza humana). Esse princípio é central. Não haveria uma GU sem a uniformidade da natureza humana; não haveria também universais linguísticos. Aqui, o pensamento é principalmente o pensamento conceitual, mas pode incluir as operações da sensação, da imaginação e da memória.

P4: Há universais linguísticos substanciais (para expressar ou analisar completamente o pensamento, usa-se sensivelmente as mesmas categorias de expressões a as mesmas regras em todas as línguas policiadas).

P5: O uso normal da palavra é uma atividade racional orientada para um fim (principalmente a comunicação).

P6: O Princípio da Analogia: a analogia deve sempre levar o melhor sobre a anomalia. As línguas se formam e evoluem respeitando certos modelos estáveis (como os paradigmas de conjugação e declinação), sem os quais elas se tornariam irregulares, as formas linguísticas se multiplicariam inutilmente, e os mecanismos da língua se confundiriam, dificultando a sua aprendizagem e deixando o seu uso mais difícil, hesitante.

P1 classifica a GU como uma teoria ideacional da linguagem. O princípio é apresentado assim por Arnauld \& Lancelot: “... o conhecimento do que acontece em nossa mente é necessário para compreender os fundamentos da gramática; e é daí que depende a diversidade das palavras que compõem o discurso" ${ }^{5}$. O mundo se divide em coisas, o pensamento em ideias e a linguagem em palavras; as palavras significam as ideias que são representações das coisas. Esse é o triângulo semiótico clássico. Os fatos relativos à linguagem e aos universais linguísticos são explicados, nas teorias ideacionais, pelas operações da mente que a linguagem expressa, principalmente a concepção (que produz as ideias ou conceitos), o juízo, cuja expressão característica é a frase declarativa,

5 Arnauld \& Lancelot, Grammaire générale et raisonnée (1660; Paris, 1997), p. 23: “Que la connaissance de ce qui se passe dans notre esprit est nécessaire pour comprendre les fondements de la grammaire; et que c'est de là que dépend la diversité des mots qui composent le discours". 
e os outros "movimentos da alma", como a interrogação, o comando ou ordem, o simples desejo e as emoções vivas. P1 é essencialmente aristotélico. Se considerarmos as partes da frase, o princípio diz o seguinte: as palavras são os signos das ideias ("símbolos dos estados da alma", dizia Aristóteles). P1 aparece nas Confissões de Agostinho (Livro $\mathrm{X}$, Capítulo 12), é adotado por Descartes; além disso, poucos filósofos o desenvolveram tanto quanto Arnauld de Port-Royal e Locke no seu famoso Ensaio de 1690. Uma mesma palavra não pode ter mais de uma significação principal no discurso; ela pode, no entanto, carregar-se de várias ideias acessórias. Reid não se afasta muito desse princípio quando escreve: "A linguagem dos homens expressa os seus pensamentos e as diversas operações de suas mentes" 6 .

P2 é comumente aceito na idade clássica. A única contestação aparece nos Princípios do conhecimento humano, de Berkeley (Introdução, § 20). Os filósofos clássicos aceitam de bom grado que a linguagem serve a outras funções: as palavras servem de "marcas" para a memória (Hobbes) e dão suporte para relembrar pensamentos abstratos (Locke); a linguagem serve também para raciocinar para si mesmo e em silêncio (Leibniz) e estende os poderes das faculdades superiores da mente dando mais exercício às mesmas (Condillac). Porém, é consensual que a comunicação é o principal motivo da "criação" das línguas, como pensava Leibniz ${ }^{7}$. A teoria ideacional da comunicação se apóia sobre um par de metáforas: comunicar é expressar os seus pensamentos, criando assim uma impressão total na mente do interlocutor. No entanto, é importante sublinhar que a teoria ideacional da comunicação não se reduz a essa simples fórmula: Arnauld, em particular, era muito consciente de que em uma mensagem total comunicada verbalmente, certas ideias são codificadas ou articuladas linguisticamente, outras são inferidas e outras não são nem codificadas nem inferidas (expressão facial, tom da voz, etc. $)^{8}$. Arnauld \& Nicole apontam para uma capacidade ou habilidade que torna possível o uso corrente da linguagem: ela é descrita como uma "penetração imperfeita da mente dos outros", como se pudéssemos "ler" (como dizia Arnauld) imperfeitamente o que acontece na mente de nossos

6 Thomas Reid (1785), Essays on the Intellectual Powers of Man, p. 27: "Men's language expresses their thoughts and the various operations of their minds". Por razões de comodidade, uso aqui a edição disponível na rede mundial, sob os cuidados de Jonathan Bennett, Copyright (C2010-2015.

7 Cf. Nouveaux Essais sur l'Entendement humain, Livro III, capítulo 1, § 2: “Je crois qu'en effet sans le désir de nous faire entendre nous n'aurions jamais formé de langage".

8 Cf. André Leclerc, Communication, Linguistic Understanding and Minimal Rationality in the Tradition of Universal Grammar, in: D. Vanderveken (org.), Logic, Thought and Action, p. 133-150. 
interlocutores. Essa capacidade, diz Arnauld, está na base da comunicação humana, porque, se nossas mentes fossem totalmente transparentes, não precisaríamos articular as nossas ideias linguisticamente, mas, se elas fossem totalmente opacas, não poderíamos deixar nada implícito, e certamente muitas "indelicadezas" seriam cometidas. Essa capacidade corresponde exatamente ao que chamamos hoje, em filosofia da mente e nas ciências cognitivas, de "mindreading". A seguinte passagem de Arnauld \& Nicole ${ }^{10}$ mostra como eles anteciparam as concepções contemporâneas:

Não se pode refletir um pouco sobre a natureza da linguagem humana sem reconhecer que ela é inteiramente baseada sobre essa penetração imperfeita da mente dos outros. É por isso que, falando com os outros, há coisas que nós não expressamos.

P3 é o mais importante dos princípios do núcleo duro. Se a natureza humana não fosse uniforme, não haveria limite de variabilidade na expressão dos pensamentos, e a GU estaria sem fundamentos. O pensamento, "considerado em geral", como dizia Condillac, é o mesmo em toda parte e para todos. As ideias se formam em toda parte da mesma maneira, inatas ou adquiridas pelos sentidos e a experiência. $O$ pensamento que importa para os grammairiens philosophes e os lógicos clássicos é o pensamento conceitual; a imaginação de um polígono de 1996 lados só apresenta uma imagem mental confusa, ao passo que a concepção da mesma figura produz uma ideia clara e distinta, a mesma para todos os geômetras de todas as épocas ${ }^{11}$. A natureza humana, sendo a mesma em toda parte, as necessidades, os desejos, as paixões, as emoções, a organização conceitual e os atos ou operações mentais são também os mesmos. Essa universalidade se apóia sobre a uniformidade da natureza humana, sobre a similaridade dos órgãos e das faculdades, e não sobre as ideias inatas dos racionalistas como pensava Chomsky. Para Condillac, por exemplo, se todas as nossas ideias vêm dos sentidos, esses são os mesmos em toda parte, e a sensação, para ele como para

9 Ver o livro recente de Alvin Goldman, Simulating Minds. The Philosophy, Psychology and Neuroscience of Mind Reading, 2006; quanto a Arnauld \& Nicole, a principal referência é La grande Perpétuité de la foi de l'Eglise catholique sur l'Eucharistie [1669-1672], edição do Abade $\mathrm{M}^{* * *}$, Paris, Imprimerie de Migne, chez l'éditeur rue d'Ambroise, Hors la Barrière d'Enfer, 1841. Essa obra é referida aqui como GP.

10 "On ne saurait faire tant soit peu réflexion sur la nature du langage humain, qu'on ne reconnaisse qu'il est tout fondé sur cette pénétration imparfaite de l'esprit des autres. Et c'est ce qui fait qu'en parlant, il y a des choses que nous n'exprimons point". (GP, Vol. 2, Livre I, p. 81).

11 Sobre isso, ver Descartes, no início da Sexta de suas Meditações Metafísicas, bem como a Lógica de Port-Royal, primeira parte, cap. 1. 
Descartes, é uma operação espiritual que se desenrola inteiramente na alma; no entanto, uma sensação se torna uma ideia só após ser transformada em "imagem" ou representação de algo pela reflexão ou razão. As operações da mente se realizam em um instante, e todas as partes de um pensamento são simultaneamente presentes na mente do agente cognitivo; é a comunicação que nos obriga a dividir ou analisar os pensamentos, para apresentá-los sucessivamente e segundo certa ordem.

A afirmação da existência de universais linguísticos (P4) é possível graças aos três primeiros princípios do núcleo duro. A linguagem é a expressão do pensamento, e esse é o mesmo em toda parte e para todos; ora, a principal função da linguagem é a comunicação dos pensamentos, e para comunicá-los com eficiência é necessário decompô-los (ou analisálos), usando os únicos signos que podemos manipular à vontade, isto é, os signos artificiais ou convencionais. Os "elementos necessários" do discurso e as regras universais de suas combinações são constitutivos de todos os sistemas de signos satisfazendo às condições para a representação completa e a comunicação eficiente dos pensamentos. Entre as tradicionais partes orationis, algumas são consideradas como mais fundamentais, porque as outras podem ser derivadas ou construídas a partir dessas. É o caso dos verbos "adjetivos", que se reduzem a uma combinação da cópula e de um particípio ("ama" = "é amando"), e dos advérbios, que são equivalentes a sintagmas preposicionais ("lentamente" = "com lentidão"). Os pronomes apenas substituem nomes e, portanto, são dispensáveis na GU clássica, uma posição hoje amplamente rejeitada na filosofia da linguagem. A existência dos pronomes se explica pelos imperativos de eficiência e elegância na comunicação. O ponto de vista da GU clássica é o da função: a existência de uma categoria de expressão em todas as línguas se justifica pela contribuição à expressão ou à análise de um juízo completo que as expressões dessa categoria dão. As frases completas são imagens dos pensamentos e devem ser formadas, de um lado, dos signos designando "a matéria de um juízo possível", isto é, o sujeito e o predicado de uma proposição, de outro lado, pelos signos ou traços sintáticos expressando a operação da mente efetuada pelo locutor: juízo, comando, interrogação, emoção viva, simples desejo, etc. De fato, as razões invocadas por Reid que justificam a diversidade das palavras nas línguas naturais são idênticas às fornecidas pelos gramáticos filósofos.

P5 não é realmente afetado pelas controvérsias gnosiológicas da época, entre os racionalistas e os empiristas. Faculdade de análise (discernimento) e de síntese (ligação), a razão permite a análise dos pensamentos e nos torna capazes de "arranjar diversamente as nossas 
palavras" (Descartes). Sobretudo, é no seu uso prático, como capacidade de escolher um meio apropriado para realizar os seus fins, que a razão interessa aqui. Só uma faculdade como essa pode explicar o uso criador da palavra, não somente como capacidade de "arranjar diversamente as palavras" para produzir frases novas, mas também como capacidade de ajustar as palavras de maneira apropriada à infinita variedade dos contextos de enunciação. É por isso que Pariente (1985, p. 54) descreve a razão como uma "capacidade ilimitada de inovações adaptadas", fazendo eco à fórmula cartesiana: "um instrumento universal que pode servir em todo tipo de situações" ("un instrument universel, qui peut servir em toutes sortes de rencontres", Discours de la méthode, p. 121). Os fatos de língua não são "arbitrários" para os grammairiens philosophes, pelo menos se entendermos por isso o mesmo que "imotivados". As convenções linguísticas não são frutos do acaso e do capricho, mesmo se o acaso e o capricho podem entrar por uma parte nessas convenções. Os signos linguísticos são "artificiais", feitos com arte, e resultam de uma escolha racionalmente fundamentada ("fondé em raison", como dizia Condillac). De outro modo, a GU não poderia ter a pretensão de "explicar" os fatos linguísticos. A universalidade das categorias e das regras na GU é assegurada, acima de tudo, pela uniformidade da natureza humana em geral, e não pelas ideias inatas dos racionalistas. Aliás, os racionalistas nunca tiveram o monopólio da razão. A rejeição das ideias inatas pelos sensualistas nunca foi uma rejeição da razão, e sim de um suposto conteúdo da razão: um conjunto de princípios inatos, a priori, de uma certeza intocável, como "o todo é maior do que cada uma de suas partes", "se uma mesma quantidade é subtraída de duas quantidades iguais, a igualdade permanece", etc. São esses princípios que Condillac chamava de "provérbios dos filósofos". De resto, podemos dizer que o racionalismo não foi mal servido pelos sensualistas. A linguagem é um meio para um fim, a obra da razão, e a comunicação é baseada sobre uma presunção de racionalidade mínima, como Arnauld \& Nicole defenderam: "supõe-se normalmente que se fala a pessoas que se afastam o menos possível da razão"12.

P6 aparece em diversos tópicos nas gramáticas filosóficas clássicas: na gênese dos nomes comuns, na teoria dos tropos (para as metáforas e outras figuras aparentadas), na teoria da origem e da evolução das línguas (para o estabelecimento das significações morfológicas e das regras sintáticas) ou para reger casos litigiosos no uso. Qual é a nominalização

12 Perpétuité de la foi de l'Eglise catholique sur l'Eucharistie, op. cit., t. 1, Livro IV, cap. VII, p. 538. 
do agente de "reação"? Se "visão" gera "visionário", então "reação" gerará "reacionário", etc. A analogia está em toda parte na língua; é ela que confere a uma língua o seu caráter regular e sistemático e que contribui para conter ou reduzir o número de anomalias (verbos irregulares, idiomatismos, etc.), que não deve ultrapassar um certo limite além do qual a aprendizagem de uma língua se torna difícil e o seu uso se torna flutuante, incerto, hesitante.

\section{A concepção clássica de mente: Descartes versus Reid}

A partir de Descartes, a alma não tem mais funções biológicas como a respiração, a circulação sanguínea e a digestão; essas são descritas e explicadas pela fisiologia, concebida como um capítulo do grande "mecanismo universal". A distinção entre a res cogitans e os seus modos (as ideias) e a res extensa e os seus modos (os objetos) é aceita por praticamente todo mundo na época: uma mente privada, invisível, indivisível e sem extensão, frente ao mundo dos objetos públicos, visíveis, extensos e divisíveis. Formamos ideias dos objetos, e as ideias são os primeiros objetos imediatos da mente. Porém, no representacionalismo clássico, nada que pertence ao mundo da res extensa pode "passar" para a mente ou ser recebida por ela. A mente aristotélica recebe dos objetos, na percepção, a forma sem a matéria. Nada disso é possível no dualismo. O interacionismo de Descartes foi logo reconhecido como inconsistente, ao passo que o ocasionalismo, o paralelismo e o sistema da harmonia pré-estabelecida pressupõem toda uma teologia racional. Arnauld, Pascal e Nicole, a Port-Royal, os empiristas em geral e os filósofos do senso comum adotaram uma postura mais humilde e consideraram como "acima da razão" esse assunto (como se relacionam as duas substâncias, pensante e extensa).

A principal nota discordante veio precisamente dos escoceses, seguidores do Dr. Reid. Ele criticou severamente o "way of ideas", que, segundo eles, leva ao imaterialismo (Berkeley), uma doutrina consistente, mas tão chocante para o senso comum que dificilmente pode ser levada a sério, ou ao ceticismo (Hume), que não lhe parece muito mais recomendável. Reid achava que as ideias como "objetos imediatos do pensamento" são uma invenção dos filósofos ("a mere fiction of philosophers"). "Ter ideias" significa o mesmo, no sentido popular, que "conceber", "imaginar" ou "apreender". Nesse sentido, ter a ideia de um objeto é, simplesmente, pensar nele. O sentido popular não é ambíguo; na verdade, é tão simples que nem precisa ser definido, e isso corresponde exatamente à posição adotada na lógica de Port-Royal. Esse sentido popular envolve (1) a mente que pensa, (2) a operação 
de conceber ou pensar e (3) o objeto dessa operação. Alguns filósofos são de opinião que é preciso acrescentar um quarto termo, a "ideia" derivada do objeto, mas isso não passa, segundo Reid, de uma opinião de alguns modernos ecoando antigas opiniões sobre a necessidade das "espécies intencionais" ou phantasmata. Como é bem sabido, Reid sempre defendeu o realismo direto e considerava entre as verdades que resultam de um acordo universal (com a exceção de alguns céticos teimosos) baseado no funcionamento natural de nossas faculdades o seguinte princípio: "Existe um mundo material, e as coisas que vemos e manipulamos são reais, e não simples ilusões e aparições" ${ }^{13}$. Na maioria dos casos, uma operação da mente deve ter um objeto distinto da própria operação. É óbvio no caso da percepção. A sensação, no entanto, é uma exceção a essa regra.

Reid fala do "mundo intelectual" e do "mundo material" e de dois sistemas: o das mentes e o dos corpos materiais. Aqui, temos só uma aparência de dualismo ou, na melhor das hipóteses, um dualismo tímido. O nosso conhecimento da mente é tão imperfeito quanto o dos corpos. Não conhecemos a essência da mente ou dos corpos, só algumas propriedades e operações ${ }^{14}$. A mente é simplesmente apresentada como "aquilo que pensa". Reid nunca chega a apresentar a mente como uma "substância" distinta das outras substâncias presentes na natureza. A natureza, diz ele, ensina-nos a atribuir todas as operações que conhecemos a uma única fonte ou a um único princípio interno, que chamamos de "mente" ou "alma"15. A originalidade de Reid reside no uso que ele faz do par poder-operação ou, de modo equivalente e mais aristotélico, do par potencialidade-atualidade. A mente como princípio ativo se manifesta nas suas operações. O modelo de mente proposto por Reid poderia ser chamado de "disposicionalista". "Poder" é um termo disposicional, como "capacidade", "habilidade", "competência, "tendência", "potencialidade", "faculdade", "aptidão", etc. Os corpos têm propriedades, e as mentes têm operações. Não há operação sem poder de operar (outra verdade de senso comum), mas a posse de um poder, claramente, não significa o seu exercício. Quem possui o poder de

13 Cf. Thomas Reid, Essays on the Intellectual Powers of Man, p. 20: "There is a material world, and the things we see and handle are real and not mere illusions and apparitions".

14 Id. ibid., p. 6: "By the mind of a man we understand whatever it is in him that thinks, remembers, reasons, wills. We don't know what the essence is of body or of mind. We know certain properties of body, and certain operations of mind, and it is only in terms of these that we can define or describe them".

15 Ibid., p. 6: "We are taught by Nature to attribute all these to one internal principle, and we call this principle of thought the 'mind' or 'soul' of a man". Ibid., p. 19: "I take it for granted that all the thoughts I am conscious of or remember are the thoughts of a single thinking principle, which I call 'myself' or 'my mind'". 
andar não deixa de possuir esse poder quando fica sentado. Considerando o contexto da época, a concepção de mente de Reid parece a menos propensa a "substancializar" a mente. Disposições não são objetos, e o mesmo vale das operações ${ }^{16}$.

As operações da mente são os modos ou as maneiras de pensar dos quais somos conscientes. Reid menciona, entre elas: ver, ouvir, deliberar, decidir, julgar, querer, amar, odiar e muitos outros. A classificação tradicional dos poderes da mente em apreensão simples (concepção), juízo e raciocínio é deficiente, segundo Reid. O conhecimento que temos de nossas próprias operações (por exemplo, o conhecimento de que "Eu penso") não é uma apreensão simples, nem um juízo nem um raciocínio. Reid vê a mesma dificuldade com a percepção de um objeto pelos sentidos e com a memória. A nova classificação dos poderes que ele propõe é muito mais complexa: (1) poderes que temos em virtude dos sentidos externos, (2) a memória, (3) a concepção, (4) o poder de analisar objetos complexos em suas partes constituintes e de fazer o caminho inverso (compor algo complexo a partir de elementos), (5) julgar, (6) raciocinar, (7) formar juízos de "gosto" (taste) e (8) a percepção moral.

\section{As operações sociais da mente}

Existe outra maneira de classificar os poderes da mente, afirma Reid. As operações da mente podem ser divididas em solitárias e sociais. Várias operações da mente podem ser realizadas por sujeitos isolados. Podemos conceber, julgar, raciocinar "à part soi et en silence", como dizia Leibniz. Não é preciso, para realizar essas operações, que haja outra pessoa presente enquanto a operação é realizada ${ }^{17}$. Mas, pedir uma informação ou questionar, prometer, comandar, testemunhar, suplicar, exortar, etc., são operações que pressupõem a existência de outros seres

16 Sobre uma concepção semelhante, ver meu artigo "Mente e 'Mente'", na Revista de Filosofia Aurora, Curitiba, v. 22, n. 30, p. 13-26, jan./jun. 2010. "O núcleo de sentido que procuramos destacar como característica mais central do conceito comum de mente é a capacidade/habilidade de representar/indicar algo, para um sujeito consciente situado." P. 21.

17 "By 'social operations' I mean ones that necessarily presuppose communication with some other thinking being. A man could understand and will, apprehend and judge and reason, even if he knew of no thinking being in the universe except himself. But when he asks for or receives information, offers or receives testimony, requests or gets a favour, gives a command to his servant or gets one from a superior, gives his word in a promise or contract, these are acts of social interaction between thinking beings, and can't occur in solitude. They presuppose understanding and will, but they also presuppose something additional to both of those, namely society with other thinking beings." P. 35. 
inteligentes capazes de compreender. As nossas operações e afecções sociais aparecem muito cedo na infância; elas pressupõem, diz Reid, "uma crença de que há outros seres pensantes". Portanto, na filosofia de Reid, há operações da mente cuja existência depende da existência de outros seres inteligentes. Em outras palavras, nem todas as operações da mente independem do ambiente social. Esse é o tipo de posição que chamamos hoje de "externismo" ou "anti-individualismo" em filosofia da mente, particularmente no que diz respeito à posse de certos conteúdos mentais. O anti-individualismo de Reid é "social", mas distinto do de Tyler Burge $^{18}$. Como a mente, segundo Reid, é essencialmente ativa, algumas de suas atividades (que ele chama de "operações") não poderiam, simplesmente, realizar-se em completo isolamento. A posição de Reid é certamente inovadora no século 18; no entanto, hoje, o mais difícil é defender a existência do que ele chama de "operações solitárias", que pareciam tão naturais a Reid e a seus predecessores.

É extremamente difícil conhecer as operações da nossa própria mente. Reid, como Locke, recomenda uma "reflexão cuidadosa" sobre elas como principal fonte de conhecimento, mas a linguagem serve para dar indicações e ponderar as intuições que podem às vezes enganar. Uma atenção cuidadosa à estrutura da linguagem é muito importante para entender as operações da mente. Reid, imediatamente, chama a atenção sobre as várias "formas do discurso" (forms of speech) que em todas as línguas expressam as operações da mente. Aqui, a tradição de pesquisa da Gramática Universal desde Port-Royal distingue entre o objeto de nosso pensamento (os conceitos, isto é, a matéria de um juízo possível) e a forma ou a maneira de nosso pensamento (principalmente o juízo, mas também outros "movimentos de nossa alma", como os desejos, o comando, a interrogação, etc.). Reid fala nesse contexto de "modos de discurso" (modes of speech) que correspondem ao que chamamos hoje de "aspectos ilocucionários do significado"19. Ninguém explorou melhor as ideias de Reid na tradição da Gramática Universal do que o seu grande amigo, o Doutor James Gregory, professor de medicina na Universidade de Edimburgo. Os Essays on the Intellectual Powers of Man de Reid são, aliás, dedicados aos seus dois melhores amigos: Dugald Stewart e James Gregory. Gregory expõe suas ideias em um texto lido em duas sessões,

${ }^{18}$ Cf. Tyler Burge, Individualism and the Mental, in: Midwest Studies in Philosophy, p. 73-122.

19 Id. Ibid., p. 27: "All languages have modes of speech by which men say what they think, give their testimony, accept or refuse, ask for information or advice, command, threaten, or implore, give their word in promises or contracts. If such operations weren't common to all mankind we wouldn't find in all languages forms of speech by which they are expressed". 
no dia 18 de junho e no dia 16 de julho de 1787, diante da Royal Society of Edinburgh ${ }^{20}$.

\section{Considerações finais: Gregory sobre modos gramaticais e modos do pensamento}

Gregory distinguiu mais rigorosamente do que qualquer outro os "modos gramaticais" (grammatical moods) dos "modos de pensamento" (moods of thought) e introduziu o conceito das operações sociais da mente na Gramática Universal, ampliando o quadro das teorias ideacionais da linguagem. Os modos podem ser considerados em relação às línguas ou relativamente ao pensamento. Os modos do pensamento e o pensamento em geral são os mesmos em toda parte e para todos, mas os modos gramaticais podem variar muito de uma língua para outra. Os modos gramaticais são todas as marcas sintáticas e os traços linguísticos que servem para expressar os modos de pensamento, também chamados de "energias" por Gregory, seguindo Harris e Monboddo, ou também de "modificações". Os modos gramaticais incluem os modos verbais, a ordem das palavras, os sinais de pontuação, o tom da voz e o uso de verbos denotando o ato de fala realizado por enunciações na primeira pessoa do singular do indicativo. As línguas naturais são defectivas quanto à expressão dos modos de pensamento, que são sempre muito mais numerosos que os modos gramaticais. Eis por que os mesmos modos gramaticais servem frequentemente para expressar diferentes modos de pensamento, que só o contexto e o tom de voz, por exemplo, permitem distinguir. "Faça isso!" pode ser um aviso, um conselho, um simples pedido, uma ordem, um comando, uma exortação ou uma súplica, dependendo de fatores contextuais (posição de autoridade do falante, a referência do "isso", a gravidade da ação a ser realizada, a capacidade do interlocutor e a sua motivação, etc.).

Assim, poucos modos de pensamento encontram uma expressão padrão nos modos gramaticais, mas é sempre possível formar um enunciado cujo verbo principal está na primeira pessoa do singular do indicativo presente, seguido por uma cláusula proposicional ou um infinitivo: "Eu lhe aviso que...", "Eu me comprometo a...", etc. Essa redução ao indicativo do fragmento não declarativo de uma língua é conhecida dos gramáticos desde Apolônio Díscolo (séc. 2 d.C.) e foi reintroduzida na teoria dos atos de fala por Austin como critério gramatical para identificar os performativos explícitos.

${ }^{20}$ Cf. James Gregory (1790), The Theory of the Moods of Verbs, nas Transactions of the Royal Society of Edinburgh. 
A enumeração dos modos de pensamento apresentada por Gregory é interessante em si. Cito-a in extenso e na língua original:

Affirming, denying, testifying, foretelling or prophecying, asking, answering, wishing, hoping, expecting, believing, knowing, doubting, supposing, stipulating, being able, commanding, praying, requesting, supplicating, loving, hating, fearing, despairing, being accustomed, wondering, admiring, warning, swearing, advising, refuting, exhorting, dissuading, encouraging, promising, threatening, and perhaps numberless other modifications of thought, for which I cannot easily find names, all admit very readily of being combined with the general import of a verb...21

Dos trinta e seis verbos da lista, mais da metade são verbos ilocucionários denotando atos ilocucionários, outros denotam atos perlocucionários (dissuadir, encorajar, etc.), outros ainda denotam estados psicológicos ou atitudes proposicionais (crer, amar, odiar, saber, admirar, recear, etc.). É um pouco mais difícil entender a presença de termos disposicionais na lista (being able, being accustomed); a explicação mais plausível é que eles foram concebidos como "poderes" da mente e porque essas expressões podem combinar-se com outros verbos. Finalmente, muitos modos de pensamento aqui mencionados são "operações sociais da mente" (comandar, prometer, suplicar, questionar, etc.).

Gregory insiste que as energias da mente que os modos gramaticais expressam são "principalmente" (chiefly) operações sociais, aquelas, diz Gregory, que implicam uma crença na existência de outro ser inteligente ao qual a operação se relaciona e que não podem ocorrer em um ser solitário. Gregory vai mais longe e parece oferecer uma quase generalização, deixando pouco espaço para as operações solitárias que acabam aparecendo como "exceções". De novo, cito in extenso a partir do texto original:

No man could be supposed even to form (not to say utter) a proposition, a question, or a command, who did not believe that there were other intelligent Beings besides himself, who might understand him. In general too, (for I admit there may be exceptions to this) the person who utters a proposition wishes to be believed, he who gives a command wishes to be obeyed, he who puts a question wishes to be answered, and all of them wish to be understood. These are all operations of thought, which cannot take place in a solitary Being ${ }^{22}$.

${ }^{21}$ Id. Ibid., p. 206-207.

22 Ibid., p. 224-225. 
A tese de Gregory poderia ser reformulada, em termos contemporâneos, da seguinte maneira: um agente cognitivo pode possuir um modo de pensamento solitário, mas ele não pode expressá-lo semanticamente, por meio de um verbo denotando o modo em questão, sem possuir um modo de pensamento social (como querer ser compreendido). Os modos de pensamento sociais estão assim na base de qualquer uso da linguagem, pois quem fala quer ser compreendido. Sem o desejo de comunicar, não haveria nem linguagem. E não se pode ter o desejo de comunicar e ser compreendido sem possuir uma crença relativa à existência de outros seres inteligentes. As operações sociais da mente são uma condição de inteligibilidade do uso corriqueiro da linguagem. A concepção de mente de Reid, com as operações sociais, permite assim uma ampliação do quadro das teorias ideacionais e aumenta ao mesmo tempo a coerência das mesmas. Ela permite uma inclusão natural de operações mentais que um sujeito solitário não pode "processar". No individualismo metodológico adotado a partir de Descartes, a princípio, todas as operações da mente e todos os estados e conteúdos mentais são suscetíveis de serem processados ou possuídos por um sujeito solitário. Mas, então, pergunta Putnam (1975), é possível estar com ciúmes de suas próprias alucinações? Se for verdade que eu estou com ciúmes, então, duas outras pessoas devem existir. Arnauld \& Lancelot diziam que ninguém pode propriamente comandar a si mesmo, e estavam certos. Mas, não perceberam a amplitude do problema: a Gramática Geral que eles criaram era assentada sobre uma concepção de mente como substância autocontida. A tradição da gramática filosófica seguiu com essa concepção até Reid sugerir uma concepção de mente que se aproxima bastante dos externistas contemporâneos, com seu realismo direto na teoria da percepção e as operações sociais da mente. Ao se afastar do solipsismo metodológico de sua época, ele permitiu assim a superação de uma limitação importante da tradição da Gramática Universal ${ }^{23}$.

\section{Referências}

N. B.: Os livros raros do século 18, mencionados no texto e nesta bibliografia, quando não houve uma reedição, foram consultados anos atrás na rica seção de microfilmes da Biblioteca da Universidade do Québec à Trois-Rivières.

ARNAULD \& LANCELOT. Grammaire générale et raisonnée. Paris: Éditions Allia, 1997 [1660].

${ }^{23}$ Quero agradecer mais uma vez Gesuína de Fátima Elias Leclerc pela leitura crítica, atenta e carinhosa deste texto. 
ARNAULD \& NICOLE. La Logique ou l'Art de penser. Paris: Flammarion, 1970 [1662]. . La grande Perpétuité de la foi de l'Eglise catholique sur l'Eucharistie [1669-1672], edição do Abade $\mathrm{M}^{* * *}$. Paris: Imprimerie de Migne, chez l'éditeur rue d'Ambroise, Hors la Barrière d'Enfer, 1841.

AUSTIN, John L. How to Do Things with Words. Oxford: Clarendon, 1962.

BEATTIE, James. The Theory of Language. Londres. Nova impressão em facsímile. Menston: Scolar Press, 1968 [1783].

BEAUZÉE, Nicholas. Grammaire générale, ou Exposition raisonnée des éléments nécessaires du Langage pour servir de fondement à l'étude de toutes les langues. Paris: Bardou, 2 Vols., 1767.

BUFFIER, Claude. Grammaire françoise sur un plan nouveau. Paris, chez Nicholas Le Clerc: Michel Brunet \& Montalant, 1709.

BURGE, Tyler. Individualism and the Mental. In: Midwest Studies in Philosophy, 4 (1979), p. 73-122. Também in: LUDLOW, P.; MARTIN, N. (orgs.). Externalism and Self-Knowledge. Stanford: CSLI Publications, 1998.

BURNETT, James (Lord Monboddo) (1773-1792). Of the Origin and Progress of Language. Edinburgh, 6 Vols. [1773, vol. 1; 1774, vol. 2]. Menston: Scholar Press, 1967.

CHOMSKY, Noam. Cartesian Linguistics. A Chapter in the History of Rationalist Thought. New York-London: Harper \& Row, 1966.

CONDILLAC. Grammaire, Tome 1 das Oeuvres philosophiques, Tome XXXIII du Corpus général des philosophes français, texte établi et présenté par G. Le Roy. Paris: P.U.F., 1947-1951 [1775].

DESTUTT DE TRACY, Antoine. Grammaire, Tome 2 des Éléments d'idéologie. Paris: Vrin, 1970 [1803].

DIDEROT \& d'ALEMBERT. Encyclopédie, ou Dictionnaire raisonnée des sciences, des arts et des métiers; édition conforme à celle de Pellet, in quarto. Berne et Lausanne: Sociétés Typographiques, 1780.

DAVIDSON, Donald. The Social Aspect of Language. In: MCGUINNESS, B.; OLIVERI, G. (orgs.). The Philosophy of Michael Dummett. Dordrecht: Kluwer Academic Publishers, 1994. Também in: DAVIDSON, Donald. Truth, Language and History. Oxford: O.U.P., 2005, p. 109-125.

DESCARTES, René. Discours de la méthode. Introdução e notas de E. Gilson. Paris: Vrin, 1966 [1637].

DU MARSAIS, César Chesneau. Oeuvres de Du Marsais. Paris: Imprimerie Pougin, 1797.

GOLDMAN, Alvin. Simulating Minds. The Philosophy, Psychology and Neuroscience of Mind Reading. Oxford: O.U.P., 2006.

GREGORY, James. The Theory of the Moods of Verbs. In: Transactions of the Royal Society of Edinburgh, [1790].

HARRIS, James. Hermès, ou Recherche philosophique sur la grammaire universelle. Tradução e notas de F. Thurot (1796), org. por A. Joly. Genève-Paris: 1972 [1751].

HUSSERL, Edmund. Recherches Logiques, tome second, La différence entre les significations indépendantes et les significations dépendantes, et l'idée de la grammaire pure, (tradução francesa de H. Elie). Paris: P.U.F., 1962 [1901]. 
LAKATOS, Imre. Falsification and the Methodology of Scientific Research Programmes. In: Philosophical Papers, Vol. 1, The Methodology of Scientific Research Programmes, org. por J. Worrall \& G.P. Currie. Cambridge: Cambridge University Press, 1977 [1970].

. The Methodology of Scientific Research Programmes. In: . Philosophical

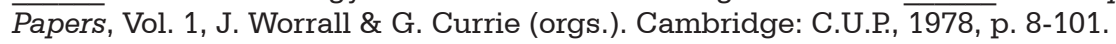

LECLERC, André. Mente e 'Mente'. In: Revista de Filosofia Aurora (Curitiba) 22:30 (jan./jun. 2010), p. 13-26.

. Communication, Linguistic Understanding and Minimal Rationality in the Tradition of Universal Grammar. In: Vanderveken, D. (org.). Logic, Thought and Action. Dordrecht: Springer, 2005, p. 133-150.

La Grammaire générale classique en tant que programme de recherche scientifique. In: Dialogue, 32,1 (1993), p. 77-94.

. Linguagem e Natureza na Gramática Universal Clássica. In: MONTENEGRO, Maria Aparecida P.; PINHEIRO, Clara Virginia de Q.; AZEVEDO Jr., Ivânio Lopes de (orgs.). Natureza e Linguagem na Filosofia. Fortaleza: Edições UFC, 2008, p. 13-35.

LEIBNIZ, Gottfried W. Nouveaux Essais sur l'Entendement humain. Paris: GarnierFlammarion, 1966 [1765].

LOKIE, Robert. Transcendental Arguments Against Eliminativism. In: British Journal for the Philosophy of Science, 54,4 (2003), p. 569-589.

MONTAGUE, Richard. Formal Philosophy. Selected Papers of Richard Montague, org. por R. Thomason. New Haven: Yale University Press, 1974.

. The Meaning of 'Meaning'. In: GUNDERSON, K. (org.). Language, Mind and

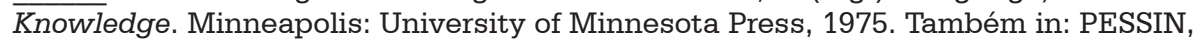
A.; GOLDBERG, S. (orgs.). The Twin-Earth Chronicles. Armonk (NY): M. E. Sharpe, 1996, p. 3-52.

QUINE, Willard van Orman. Word and Object. Cambridge (MA): MIT Press, 1960.

PARIENTE, Jean-Claude. L'Analyse du langage à Port-Royal. Six études logicogrammaticales. Paris: Éd. de Minuit, 1985.

REID, Thomas. Essays on the Intellectual Powers of Man. Edição disponível na rede mundial sob os cuidados de Jonathan Bennett, Copyright (C)2010-2015 [1785].

Press, 1969.

. Essays on the Intellectual Powers of Man. Cambridge (MA)-Londres: MIT

WITTGENSTEIN, Ludwig. Philosophical Investigations. Oxford: Blackwell, 1953. 